\title{
Oferta Pública de Ações e Estrutura de Capital: Uma Análise a Partir das Heurísticas do Otimismo e Excesso de Confiança
}

\section{Initial Public Offering and Capital Structure: An Analysis Based On Heuristics Of Optimism And Overconfidence}

\author{
JEFFERSON PEREIRA ANDRADE (D) \\ WENNER GLAUCIO LOPES LUCENA (D)
}

\section{RESUMO}

Embora exista uma série de teorias que buscam explicar a definição da estrutura de capital, as pesquisas comportamentais têm evidenciado alguns gaps relacionando a atuação dos gestores nesse processo. A confiança pode conduzir o gestor a subestimar os riscos e tomar decisões erronias, afetando essas decisões. $\mathrm{O}$ objetivo deste estudo é verificar a relação entre a confiança gerencial e a estrutura de capital de companhias que realizaram ofertas públicas iniciais entre 2004 a 2017, para isso, utilizou-se a alavancagem no curto prazo, longo prazo e total como proxy para a estrutura de capital, e o índice geral de confiança de Kermani, Kargar e Zarei (2014) para caracterizar o excesso de confiança. Para estabelecer as relações, utilizou-se a correlação de Pearson, e regressões múltiplas. Também foram utilizadas o tamanho da empresa, rentabilidade, tangibilidade e a oportunidade de crescimento como variáveis de controle. A análise do excesso de confiança evidenciou se trata de uma característica generalizada, não sendo verificado apenas em um gestor ou uma empresa. Quanto a relação do excesso de confiança com a estrutura de capital verificou-se que os coeficientes das regressões foram positivos, entretanto não foram significativos sugerindo que o excesso de confiança embora seja generalizado ele não se relaciona a situação específica das ofertas públicas iniciais.

Palavras-chave: Otimismo. Excesso de confiança. Estrutura de capital. IPO. 


\section{Abstract}

Although there are a number of theories that seek to explain the definition of the capital structure, behavioral research has evidenced some gaps relating the performance of managers in this process. Confidence can lead the manager to underestimate risks and make erroneous decisions, affecting those decisions. The objective of this study is to verify the relationship between the managerial trust and the capital structure of companies that made initial public offerings between 2004 and 2017. For this purpose, short-term, long-term and total leverage was used as proxy for the structure of capital, and Kermani, Kargar and Zarei's general confidence index (2014) to characterize overconfidence. Pearson's correlation was used to establish the relations, and multiple regressions. Company size, profitability, tangibility and the opportunity for growth as control variables were also used. The analysis of overconfidence showed that it is a generalized characteristic, not being verified only in a manager or a company. Regarding the relationship between overconfidence and the capital structure, it was found that the regression coefficients were positive, however they were not significant, suggesting that overconfidence, although generalized, is not related to the specific situation of the initial public offerings.

Keywords: Optimism. Overconfidence. Capital structure. IPO.

\section{INTRODUÇÃo}

Diante da relevância da Estrutura de Capital para uma empresa, a literatura financeira tem concentrado esforços para explicar quais fatores são determinantes na sua definição, o que implicou no desenvolvimento de inúmeras teorias como, a Teoria do Efeito Fiscal, a Teoria dos Custos de Falência, a Teoria da Agência, a Teoria da Informação Assimétrica, a Hierarquia das Fontes de Financiamento e a Teoria de Ciclo de Vida (Cavalheiro, 2015). Embora distintas, essas teorias tentam evidenciar uma maneira de se estabelecer o equilíbrio ótimo entre o capital próprio e de terceiros, permitindo equalizar os riscos e benefícios inerentes a cada fonte de financiamento.

Mesmo após décadas da publicação do trabalho seminal de Modigliani e Miller (1958) e o desenvolvimento das várias teorias relacionadas a estrutura de capital, a literatura acerca das decisões 
de financiamento são limitadas. Sabe-se muito mais sobre táticas de financiamento (como por exemplo, o design econômico eficiente das fontes de financiamento) do que sobre as estratégias que a envolvem (Myers, 2001). Além disso, o conhecimento gerado por essas teorias é resultado a presunção de processos de decisão racionalista.

Com o advento da Teoria Comportamental as pesquisas em finanças passaram a englobar aspectos humanos as questões clássicas. Tradicionalmente um dos pilares das finanças tradicionais corresponde ao princípio da racionalidade (assumida nas teorias que explicam a estrutura de capital), entretanto o paradigma das finanças comportamentais sugere que o homem é influenciado pelo seu aspecto cognitivo, principalmente no que se refere ao seu processo decisório (Shefrin, 2001). Como consequência, muitas das preferências que dão base a escolha de fontes de financiamento, e que são descritas nas teorias racionalistas da estrutura de capital podem ser contestadas ou confirmadas por meio de uma abordagem comportamental.

Muitas das atitudes humanas são resultado de sua personalidade (Mccrae \& Costa Júnior, 1997), a qual segundo Paunonen (1998) é composta de uma série de fatores denominados traços de personalidade. Um desses traços corresponde a confiança, que desempenha um papel fundamental no processo decisório gerencial, podendo conduzir o tomador de decisão ao erro.

O excesso de confiança que também é denominado otimismo, corresponde ao traço de personalidade mais frequente nas finanças comportamentais. Segundo, Barros e Silveira (2008) existem evidências suficiente para se acreditar os gestores são excessivamente confiantes, o que pode implicar em julgamento que minimizam riscos no desempenho das suas atividades de maneira a culminar em um resultado acentuadamente positivo ou negativo.

Ao estudar os efeitos do excesso de confiança do Chief Executive Office (CEO) sobre o processo decisório estratégico das empresas, Langabeer II e Dellifraine (2014) verificaram que uma maior confiança do CEO direciona o processo decisório para o incrementalismo que corresponde a um modelo decisório que contrasta como o modelo racional ao admitir a imperfeição do processo, e tornando o processo mais sucessível aos traços de personalidade. Como consequência 
do processo decisório estratégico, a estrutura de capital também é afetada pelo excesso de confiança.

Em seu estudo com empresas brasileira Barros e Silveira (2008) verificaram que gestores excessivamente confiantes tendem a utilizar-se de uma maior alavancagem financeira, Costa, Correia e Lucena (2017) encontraram o mesmo resultado ao analisarem empresas brasileiras e americanas, já Araújo et al. (2017) verificou que os traços de personalidade possuem grande relação com a estrutura de capital de pequenas e médias empresas brasileiras, sendo preferencial o uso de recursos internos.

Embora nos os trabalhos de Barros e Silveira (2008), Araújo et al. (2017) e Costa, Correia e Lucena (2017) tenha ficado evidente a preferência de gestores confiantes por recursos internos, nenhum desses trabalhos teve como foco empresas que estavam passado por mudanças mais acentuadas em suas fontes de financiamento como durante o processo de Oferta Pública de ações, o que motivou a seguinte questão de pesquisa: Qual a influência do excesso de confiança gerencial na definição da estrutura de capital de empresas que realizaram Ofertas Públicas de Ações?

O objetivo da presente pesquisa é verificar qual a influência do excesso de confiança gerencial na definição da estrutura de capital de empresas que realizaram Ofertas Públicas de Ações. Embora existam pesquisas anteriores avaliando a relação objeto de estudo, ainda é necessário o desenvolvimento de pesquisas que versem sobre o tema, dada as limitações inerentes a mensuração de um traço de personalidade. Geralmente a para se mensurar o excesso de confiança as pesquisas utilizam-se de variáveis proxies, que podem conduzir a relações espúrias. Diferentemente das metodologias utilizadas nas pesquisas de Barros e Silveira (2008), Araújo et al. (2017) e Costa, Correia e Lucena (2017) para se mensurar o excesso de confiança nas pesquisas anteriores o presente estudo buscou contribuir para literatura usando-se do índice de que excesso de confiança desenvolvido por Kermani, Kargar e Zarei (2014). 


\section{REFERENCIAL TEÓRICO}

\subsection{Estrutura de capital}

No contexto das finanças corporativas a estrutura de capital corresponde a um dos assuntos mais complexos e polêmicos (Cunha, Santos \& Haveroth, 2017). Para Cavalheiro, Vieira e Valcanover (2016) ela pode ser definida como a proporção entre capital próprio e de terceiros, obtidos por uma empresa e utilizado para sustentarem seus ativos, o que a torna um dos principais responsáveis pelo equilíbrio financeiro. Deste modo, as decisões que envolvem a estrutura de capital não devem ocorrer ao acaso, pois muitos estudos apontam a sua conotação estratégica.

Essas decisões devem partir da premissa que as características inerentes às fontes de financiamento devem ser ponderadas, uma vez que cada uma delas implica em uma série de benefícios, custos, risco e obrigações distintas (Fonseca, Silveira \& Hiratuka, 2016; Junqueira et al., 2017). Além disso, de acordo Mayers (1984) as mudanças na estrutura de capital são capazes de transmitir informações para os investidores, afetando o valor de mercado das companhias.

Mesmo diante de sua relevância e conotação estratégica, na literatura financeira falta uma teoria universal para a escolha equitativa da dívida empresarial (estrutura de capital), e não existe razão para que se espere por uma (Myers, 2001). Inúmeras teorias impulsionadas pelo trabalho de Modigliani e Miller (1958) buscaram estabelecer a estrutura de capital ideal, entretanto Medeiros et al. (2017) e Almendra et al. (2017) afirmam que boa parte dos estudos desenvolvido na atualidade tem como foco as duas principais teorias envolvendo a estrutura de capital: O Trade-off e a Pecking Order.

Para a Teoria Trade-off as empresas procuram atingir níveis ótimos de endividamento, considerando os custos associados à dívida, bem como seus benefícios (Medeiros et al., 2017). O Trade-off representa uma estratégia estática que busca equilibrar a relação dívida-valor-alvo (Myers, 1984). Segundo a Teoria, não existe uma ordem de preferência ou hierarquia das fontes de financiamento, apenas o custo e benefícios que vai implicar em sua utilização ou não (Araújo et al, 2017). 
A Teoria Pecking Order diz que a empresa vai buscar equidade quando o fluxo de caixa interno não é suficiente para financiar despesas de capital. Assim, o montante da dívida refletirá a necessidade cumulativa de recursos externos a empresa (Myers, 2001). Contrário à Teoria do Trade-off a Pecking Order defende a existência uma hierarquia ótima para o uso de diferentes fontes de financiamento. As empresas primeiro se utilizam do capital interno disponível e posteriormente recorrem ao financiamento externo, sendo a emissão de capital próprio aplicado apenas quando a oferta de crédito é limitada (Medeiros et. al., 2017). Como consequência a empresa não possui um índice de endividamento bem definido quando a estrutura de capital se baseia na Pecking Order (Mayers, 1984).

Ambas as teorias partem do princípio que as características das fontes de financiamento são fatores preponderantes para a escolha da estrutura de capital, entretanto pesquisas têm demonstrado esse como apenas um dos fatores. As estratégias de financiamento de uma empresa e o lapso temporal por ela definido são importantes ferramentas na definição da sua estrutura de capital. Estratégias de longo prazo podem demandar financiamento externo obtido através da Oferta Pública de ações (Cao \& Montezano, 2016).

A natureza das organizações também pode direcioná-la a uma determinada estrutura de capital. A análise do ciclo de vida empresarial tem demonstrado uma tendência a abertura de capital quando as empresas atingem a maturidade, nessa fase a oferta de crédito é maior e as possibilidades de barganha envolvendo a empresa também (Zilio, 2012; Oliveira \& Martelanc, 2014; Cunha, Santos \& Haveroth, 2017). Embora exista uma certa consolidação da proposição do ciclo de vida, ainda assim há um desacordo quanto a sua relação com a estrutura de capital (La Racca, La Rocca \& Cariola, 2009).

Sejam as premissas contidas nessas teorias determinantes ou não, da estrutura de capital, as pesquisas em finanças comportamentais têm evidenciado a sua negligência envolvendo os aspectos humanos inerente a figura dos gestores, entretanto, considerando que as teorias correspondem a simplificações da realidade, e por isso são limitadas a um determinado escopo, é de se esperar que elas não sejam capazes de abranger as decisões que envolvem a estrutura de capital em sua plenitude (Ferreira \& Yu, 2003). 


\subsection{Teoria dos traços de personalidade}

A teoria dos traços de personalidade busca encontrar na distinção entre os indivíduos uma forma de estimular a busca por padrões que explique o comportamento diferenciado entre eles (Basso \& Espartel, 2015). Os traços de personalidade correspondem a abstrações que não podem ser diretamente medidas e devem ser inferidos de padrões complexos de comportamento encoberto (Mccrae \& Costa Júnior, 1987).

Segundo Mccrae e Costa Júnior (1997) a personalidade corresponde a um reflexo do conjunto de partes ou traços que resulta na plenitude do ser. As variáveis que compõem a personalidade são organizadas de maneira hierárquica, de acordo com a amplitude dos domínios de comportamento. Características pontuais de comportamento são a base da hierarquia e são caracterizadas pelas respostas específicas e habitual, enquanto o topo é representado por fatores preponderantes da personalidade (Paunonen, 1998).

Segundo Paunonen (1998) existem divergências quanto ao entendimento dos fatores preponderantes de personalidade, o que implica eles não são estáticos e únicos. A partir dos traços de personalidade Cavalheiro (2015) aponta o surgimento a ramificação conhecida como traços de personalidade gerencial aplicado ao ambiente corporativo. De acordo com o autor, a área tem como precursor o trabalho de Edwin Ghiselli que identificou seis traços importantes inerente a personalidade dos gestores: Capacidade de supervisão, necessidade de realização ocupacional, inteligência, determinação, autoconfiança e iniciativa.

Da perspectiva psicológica dos traços de personalidade originam-se os atalhos mentais denominados de vieses cognitivos, capazes de influenciar as decisões financeiras dos indivíduos (Cavalheiro, 2015).

O principal atalho mental designado na literatura é o excesso de confiança, hora também denominado otimismo (Tonin et al., 2015; Costa; Correia \& Lucena, 2017). O otimismo se caracteriza como sendo uma questão de expectativas futuras as quais os indivíduos têm sentimentos fortes capazes de motivá-los (Peterson, 2000).

Nos gestores o otimismo interfere de maneira a subestimar a probabilidade do bom resultado e subestimam a probabilidade do 
mau resultado (Heaton, 2002). Assim como o otimismo influencia as decisões de maneira que as probabilidades de fracasso são subestimadas pelos gestores.

\subsection{Hipótese de pesquisa}

No ambiente corporativo os estudos de vieses comportamentais correspondem a um fator de grande importância, uma vez que segundo Karnani; Kargar; Zarei (2014) eles podem ocasionar a destruição de valor da entidade. No que se refere a sua relação do viés do otimismo com a estrutura de capital, as pesquisas sugerem que gestores otimistas se utilizam preferencialmente de recursos próprios (Barros \& Silveira, 2008; Cavalheiro, 2015; Silva et al.,2017; Costa, Correia \& Lucena, 2017).

Em seu trabalho, Barros e Silveira (2008) analisaram a partir da variável dummy gestor empreendedor a relação do traço de personalidade do excesso de confiança e a estrutura de capital em 153 empresas de capital aberto entre 1998 e 2003. Como resultado os autores concluíram que o excesso de confiança corresponde a um dos principais determinantes da estrutura de capital e que gestores mais excessivamente confiantes utilizam-se de uma maior proporção de capital de próprio.

Cavalheiro (2015) estudou o impacto do otimismo em 625 empresas consideradas de micro e pequeno porte. Diferentemente da pesquisa anterior, essa foi efetuada com empresas de capital fechado, a partir de um survey, analisado por meio da técnica de equações estruturais. Como resultado o autor verificou a existência de relação positiva entre o otimismo gerencial e o excesso de confiança dos gestores na estrutura de capital dessas empresas.

Silva et al. (2017) estudou a relação dos vieses do otimismo e o excesso de confiança e a estrutura de capital de em empresas cinquentenária e não cinquentenárias. Usando as ações em tesouraria como proxy para as variáveis comportamentais os autores concluíram que empresas não cinquentenária possuem gestores mais excessivamente confiantes do que as empresas não cinquentenárias, além disso elas apresentam maior grau de alavancagem.

Costa; Correia e Lucena (2017) utilizando uma amostra composta por empresas listada na BM\&FBOVESPA e na NYSE entre 
2010 a 2015, por meio do índice de excesso de confiança desenvolvido por eles, encontraram relações positivas e significativas entre o otimismo e o excesso de confianças nas empresas de ambas as bolsas, sendo os efeitos mais acentuados em gestores das companhias listadas na NYSE.

Os resultados dos trabalhos de Barros e Silveira (2008), Cavalheiro (2015), Silva et al. (2017), Costa; Correia e Lucena (2017) sugerem que assim como defendem Brown e Sarma (2007) o excesso de confiança corresponde a um fenômeno generalizado, fornecendo base para a seguinte hipótese de pesquisa:

Hipótese 1: $\mathrm{O}$ excesso de confiança gerencial está relacionado positivamente a estrutura de capital de empresas que realizaram ofertas públicas.

\section{Metodologia}

\subsection{Amostra e coleta de dados}

A amostra da pesquisa foi definida a partir do universo de empresas que realizam ofertas públicas iniciais na Brasil, Bolsa, Balcão (B3) entre os anos de 2004 a 2017. Optou-se por utilizar empresas que realizaram IPO em razão da sua clara mudança na estrutura de capital, uma vez que essas empresas passaram a emitir títulos patrimoniais como forma de financiamento.

Quanto ao horizonte temporal, ele foi definido a partir de 2004 em razão da expansão de crédito ocorrida neste período no Brasil, e que influenciou a retomada da abertura de capital no país (Pinheiro, 2012; Fonseca, Silveira \& Hiratuka, 2016).

De acordo com dados da Brasil, Bolsa, Balcão (2018) foram realizadas 300 novas ofertas públicas de vendas entre 2004 a 2017, sendo 145 Ofertas Públicas Iniciais, as demais correspondem a Ofertas Subsequentes. A partir das 145 empresas chegou-se a uma amostra pesquisável de 107 empresas conforme demonstrado na tabela 1. 
Tabela 1 - Composição da amostra

\begin{tabular}{lll}
\hline Item & Número de empresas & Percentual (\%) \\
\hline Total de IPO entre 2004 e 2017 & 145 & $100 \%$ \\
(-) Empresas do setor financeiro & 19 & $13 \%$ \\
(-) Empresas com indisponibili- & 19 & $13 \%$ \\
dade de dados & & \\
(=) Amostra final & 107 & $74 \%$ \\
\hline
\end{tabular}

Fonte: Dados da pesquisa (2018).

Dentre o total de empresas que realizam IPO, 19 delas foram excluídas da amostra em razão de pertencerem ao setor financeiro e estarem sujeitas a regulamentação diferenciada, o que resultou em 126 empresas potencialmente pesquisáveis.

Para cada uma dessas empresas foi identificada a data de início das negociações das ofertas de ações (primária e secundária) e coletadas informações nas Demonstração Financeira Padronizada (DFP) anterior e posterior a essa data, permitindo assim a formação um cross-section com os dados coletados. Devido algumas empresas não disponibilizarem essas informações elas foram excluídas da amostra, o que resultou na amostra final de 107 empresas.

\subsection{Procedimentos metodológicos}

Considerando o objetivo da presente pesquisa, para avaliar a influência do excesso de confiança gerencial na estrutura de capital das empresas que realizam ofertas públicas, a pesquisa foi desenvolvida em duas etapas. A primeira delas direcionada para o cálculo das variáveis de interesse, e a segunda destinada a caracterização, e relação dessas variáveis.

Para identificar o grau de otimismo gerencial, foi utilizado o índice geral de confiança proposto por Kermani, Kargar e Zarei (2014), que tem como base os investimentos efetuados em ativos e calculado por meio de uma regressão simples indicada abaixo.

$$
\Delta \text { Vendas }=\beta_{0}+\beta_{1}^{*} \Delta \text { Ativos }+\varepsilon
$$


O modelo proposto por Kermani, Kargar e Zarei (2014) tem como fundamento os trabalhos de Malmendier e Tate $(2005,2008)$ e a relação encontrada pelos autores de que gestores excessivamente confiantes em situação de inexistência de fontes externas de financiamento tendem a serem mais propensos a realizarem investimentos. De acordo com o modelo descrito na equação 1 a variação das vendas ( $\Delta$ Vendas) é explicada pela variação dos ativos ( $\Delta$ Ativos) e o termo de erro $(\varepsilon)$ corresponde ao indicador de confiança dos gestores.

Segundo Kermani, Kargar e Zarei (2014) o sinal positivo do termo de erro indica excesso de confiança gerencial, enquanto que os sinais negativos implicam pessimismo do gestor. Para a viabilização do modelo, o crescimento das vendas e o crescimento dos ativos foram calculados pela diferença apurada entre a primeira demonstração contábil depois da oferta pública e a última antes da oferta pública.

No que se refere a estrutura de capital, utilizou-se como base na literatura existente, os indicadores de endividamento para mensurá-la conforme demonstrado na tabela 2.

Tabela 2 - Variáveis dependentes

\begin{tabular}{|c|c|c|c|}
\hline $\begin{array}{l}\text { DESCRI- } \\
\text { ÇÃ }\end{array}$ & $\begin{array}{l}\text { ABRE- } \\
\text { VIAÇÃO }\end{array}$ & CÁLCULO & AUTORES \\
\hline $\begin{array}{l}\text { Endivi- } \\
\text { damento } \\
\text { de curto } \\
\text { prazo }\end{array}$ & END_CP & $\begin{array}{l}\text { Passivo circu- } \\
\text { lante/ Ativo } \\
\text { total }\end{array}$ & $\begin{array}{l}\text { Cavalcante et al. (2016) } \\
\text { Fonseca, Silveira e Hiratuka } \\
\text { (2016) } \\
\text { Araújo et al. (2017) }\end{array}$ \\
\hline $\begin{array}{l}\text { Endivi- } \\
\text { damento } \\
\text { de longo } \\
\text { prazo }\end{array}$ & END_LP & $\begin{array}{l}\text { Passivo não cir- } \\
\text { culante / Ativo } \\
\text { total }\end{array}$ & $\begin{array}{l}\text { Cavalcante et al. (2016) } \\
\text { Fonseca, Silveira e Hiratuka } \\
\text { (2016) } \\
\text { Araújo et al. (2017) }\end{array}$ \\
\hline $\begin{array}{l}\text { Endivi- } \\
\text { damento } \\
\text { total }\end{array}$ & $\begin{array}{l}\text { END_- } \\
\text { TOT }^{-}\end{array}$ & $\begin{array}{l}\text { Total de passi- } \\
\text { vo/ Ativo total }\end{array}$ & $\begin{array}{l}\text { Cavalcante et al. (2016) } \\
\text { Fonseca, Silveira e Hiratuka } \\
\text { (2016) } \\
\text { Araújo et al. (2017) } \\
\text { Junqueira et al. (2017) } \\
\text { Barros e Silveira (2008) }\end{array}$ \\
\hline
\end{tabular}

Fonte: Dados da pesquisa (2018). 
A estrutura de capital foi mensurada a partir de três perspectivas estratégicas, no curto prazo, longo prazo e total, pois como demonstrado por Cavalcante et al. (2017) esses indicadores sofrem o impacto de determinadas variáveis de maneira diferente tornando adequado considerá-los separadamente. Também foram definidas com base na revisão da literatura as variáveis de controle dispostas na tabela 3.

Tabela 3 - Variáveis de controle

\begin{tabular}{|c|c|c|c|}
\hline VARIÁVEL & $\begin{array}{l}\text { ABRE- } \\
\text { VIAÇÃO }\end{array}$ & DESCRIÇÃO & AUTORES \\
\hline \multirow{4}{*}{ Tamanho } & \multirow{4}{*}{ TAM } & \multirow{4}{*}{$\begin{array}{l}\text { Mensurado } \\
\text { pelas vendas } \\
\text { e pelo total } \\
\text { de ativos da } \\
\text { empresa }\end{array}$} & Barros e Silveira (2008) \\
\hline & & & Araújo et al. (2017) \\
\hline & & & Cavalcante et al. (2016) \\
\hline & & & Bastos e Nakamura (2009). \\
\hline \multirow{5}{*}{$\begin{array}{l}\text { Lucrativi- } \\
\text { dade }\end{array}$} & \multirow{5}{*}{ LUC } & \multirow{5}{*}{$\begin{array}{l}\text { EBIT/Pa- } \\
\text { trimônio } \\
\text { líquido }\end{array}$} & Barros e Silveira (2008) \\
\hline & & & Araújo et al. (2017) \\
\hline & & & Cavalcante et al. (2016) \\
\hline & & & Bastos e Nakamura (2009). \\
\hline & & & $\begin{array}{l}\text { Fonseca, Silveira e Hiratuka } \\
(2016)\end{array}$ \\
\hline \multirow{4}{*}{$\begin{array}{l}\text { Tangibili- } \\
\text { dade }\end{array}$} & \multirow{4}{*}{ TAG } & \multirow{4}{*}{$\begin{array}{l}\text { (Total de } \\
\text { ativo imo- } \\
\text { bilizado }+ \\
\text { Estoque) / } \\
\text { Ativo total }\end{array}$} & Barros e Silveira (2008) \\
\hline & & & Araújo et al. (2017) \\
\hline & & & Bastos e Nakamura (2009). \\
\hline & & & $\begin{array}{l}\text { Fonseca, Silveira e Hiratuka } \\
(2016)\end{array}$ \\
\hline $\begin{array}{l}\text { Oportuni- } \\
\text { dade de } \\
\text { crescimento }\end{array}$ & OPC & $\begin{array}{l}\text { Variação das } \\
\text { vendas }\end{array}$ & $\begin{array}{l}\text { Fonseca, Silveira e Hiratuka } \\
\text { (2016) }\end{array}$ \\
\hline
\end{tabular}

Fonte: Dados da pesquisa (2018).

Na segunda etapa de pesquisa foram utilizados procedimentos estatísticos como a análise descritiva para fornecer uma visão geral dos dados, a correlação de Pearson e regressões múltiplas, estimada pelo método dos mínimos quadrados ordinários (MQO) para avaliar as relações existentes. 


\section{RESULTADOS}

Em uma análise preliminar dos resultados, foi verificado a distribuição dos IPOs ao longo do período de estudo. Dentre as 107 empresas que abriram capital no Brasil, e que compõem amostra, $57 \%$ abriram capital até o ano de 2007, sendo este ano o ápice das ofertas públicas iniciais quando houveram 33 IPOs. Após esse período o número de IPO reduziu-se principalmente como resultado da crise financeira internacional. Na amostra apesar do fato que os dados da Brasil, Bolsa, Balcão (2018) apontarem apenas 1 IPO no ano de 2014 e um em 2015, as empresas em questão não constavam na amostra, pois no ano de 2015 o único IPO foi de uma seguradora, já no ano de 2014 a empresa não apresentava dados.

No que se refere aos dados dessas empresas, essas sofreram uma análise descritiva e os resultados estão dispostos na tabela 4. Essa análise foi fundamental para a identificação de possíveis problemas econométricos e para o cálculo do Índice Geral de Confiança.

Tabela 4 - Análise descritiva das Ofertas Públicas Iniciais

\begin{tabular}{l|l|l|l|l|l}
\hline Variáveis & OBS & Média & $\begin{array}{l}\text { Desvio } \\
\text { padrão }\end{array}$ & Mínimo & Máximo \\
\hline END_CP & 107 & 0,368151 & 1,944886 & 0,000398 & 20,22294 \\
\hline END_LP & 107 & 1,123387 & 9,955363 & 0,000000 & 103,1276 \\
\hline END_TOT & 107 & 1,491538 & 11,89388 & 0,000525 & 123,3506 \\
\hline EXC_CONF & 85 & $-1,95+\mathrm{E}-7$ & 39,10031 & $-354,8387$ & 35,62297 \\
\hline TAM & 107 & $1,85 \mathrm{E}+07$ & $1,22 \mathrm{E}+08$ & 3095,000 & $1,17 \mathrm{E}+09$ \\
\hline LUC & 107 & 0,057678 & 0,272707 & $-1,140906$ & 1,570719 \\
\hline TAN & 107 & 0,191457 & 0,199775 & 0,000000 & 0,700320 \\
\hline OPC & 107 & $-880221,7$ & $1,06 \mathrm{E}+07$ & $-1,03 \mathrm{E}+08$ & $2,30 \mathrm{E}+07$ \\
\hline
\end{tabular}

Fonte: Dados da pesquisa (2018).

No curto prazo as empresas apresentaram alavancagem média de 0,36 , o que se demonstra ligeiramente maior do que aquela apresentada pelas empresas do IBRX100 (23\%) (ARAÚJO et al., 2017), pelas empresas adepta do novo mercado (26\%) e pelas empresas com melhores práticas de governança corporativa (24\%) (Fonseca, 
Silveira \& Hiratuka, 2016). Já no que se refere a alavancagem de médio e longo, apesar de inconsistente com os trabalhos de Fonseca, Silveira e Hiratuka (2016); Araújo et al. (2017) e Costa, Correia e Lucena (2017), uma vez que eles excederam os $100 \%$, ele foi fortemente influenciado pela alta dispersão dos dados provocado pela empresa Santo Brasil Participações cujo IPO se deu em 13 de outubro de 2016, e seu primeiro balanço patrimonial após a data do IPO apresentou patrimônio líquido negativo.

Ainda com relação a alavancagem, algumas empresas apresentam endividamento próximo a 0 , implicando em uma preferência por financiamento de terceiro através de títulos patrimoniais, entretanto isso não implica que a empresa possua débito igual 0 e sim que possuem débitos irrisório em relação ao ativo total (A empresa Multiplos S. A. que realizou IPO em 05 de fevereiro de 2010, por exemplo apresentou em sua primeira DFP um passivo não circulante de 0 e um ativo de total de $\mathrm{R} \$ 1.403 .549,00$ mil conferindo a empresa uma alavancagem de curto prazo de $0 \%$ ).

A variável utilizada para mensurar o excesso de confiança dos gestores (EXC_CON) corresponde aos resíduos da regressão resultante da equação 1, proposta por Kermani, Kargar e Zarei (2014). Devido a metodologia desenvolvida pelos autores para contornar os efeitos da amplitude e variabilidade dos dados, e devido o fato de algumas empresas não apresentarem receita referente a venda de produtos ou serviço, impossibilitando o cálculo das variações (Divisão por zero), houve uma perda de (20\%) das observações, justiçando a diferença evidenciada na tabela 4 .

Assim como encontrado por Kermani, Kargar e Zarei (2014) e Tonin et al. (2016) ao aplicarem o índice geral de confiança a média dos resíduos foi negativa, o que implicaria na ausência do excesso de confiança dos gestores, porém, o auto desvio padrão, alinhado a alta amplitude dos dados (aproximadamente 319) justificam o indicador, de todas as empresas apenas uma apresentou indicador negativo, porém extremamente acentuado, indicando a existência do excesso de confiança dos gestores, e corroborando com a ideia de Brown e Sarma (2007) ao afirmarem que o excesso de confiança trata-se de um processo generalizado. 
Devido ao tamanho das organizações se relacionar tanto a escolha do IPO como fonte de financiamento (Zilio, 2012), como ao excesso de confiança do CEO (Langabeer II \& Dellifraine, 2014) ela foi adotada como variável de controle. Empresas grande tendem a optarem pela abertura de capital e atraem CEO mais excessivamente confiante. Considerando classificação utilizada pela lei 11.638/07 (são consideradas empresas de grande porte aquelas com ativo acima de $\mathrm{R} \$ 240$ milhões) e o valor mínimo apresentado na estatística descritiva da variável verifica-se que nem todas as empresas da amostra podem ser consideradas de grande porte.

A rentabilidade mensurada pela razão entre os juros antes dos juros e impostos e o patrimônio líquido (EBIT/Patrimônio Líquido) apresentam média de 0,05 e desvio padrão de 0,27. O menor desempenho foi apurado pela empresa Tempo participações que abriu capital em 19 de dezembro de 2007, e neste período apurou um prejuízo líquido $\mathrm{R} \$ 76.735,00$. O maior desempenho foi de aproximado de 1,57 apresentado pela Redecard que abriu capital em 13 de setembro de 2007 e apresentou lucro líquido no período de $\mathrm{R} \$ 700.765,00$.

Quanto a tangibilidade apontada por Araújo et al. (2017) como a garantia para os riscos assumidos no endividamento, não é possível verificar uma tendência como nos trabalhos de Barros e Silveira (2008), Fonseca, Silveira e Hiratuka (2016) e Araújo et al. (2017). As médias de tangibilidade encontrada pelos autores diferem entre si e também dá aqui encontrada. Na amostra aqui analisada, verificou-se uma tangibilidade média de 0,19 sendo mais próxima a encontrada por Araújo et al. (2017) de 0,24 nas empresas do IBRX100.

A última variável (oportunidade de crescimento) mensurada pela diferença entre as vendas nos anos de análise, apresentou média de -880221, indicando uma redução das vendas entre o período anterior e o período posterior ao IPO, entretanto existe uma grande amplitude dos dados o que motivou a utilização do logaritmo natural da variável mais 1, garantindo assim a presença de empresas com variabilidade 0 .

Inicialmente para análise das relações entre as variáveis pesquisadas empregou-se a correlação de Pearson, cujos resultado estão apresentados na tabela 5 . 
Tabela 5 - Correlação de Pearson das variáveis estudadas

\begin{tabular}{|c|c|c|c|c|c|c|c|c|}
\hline & END_CP & END_LP & $\begin{array}{l}\text { END_ } \\
\text { TOT }\end{array}$ & $\begin{array}{l}\mathrm{EXC}_{-} \\
\mathrm{CONF}\end{array}$ & TAM & LUC & TAG & OPC \\
\hline END_CP & 1 & & & & & & & \\
\hline \multirow[t]{2}{*}{ END_LP } & 0,9961 & 1 & & & & & & \\
\hline & 0,0000 & & & & & & & \\
\hline \multirow[t]{2}{*}{ END_TOT } & 0,9973 & 0,9999 & 1 & & & & & \\
\hline & 0,0000 & 0,0000 & & & & & & \\
\hline \multicolumn{9}{|l|}{ EXC_ } \\
\hline \multirow[t]{2}{*}{ CONF } & 0,1388 & 0,1259 & 0,2172 & 1 & & & & \\
\hline & 0,2051 & 0,2510 & 0,0459 & & & & & \\
\hline \multirow[t]{2}{*}{ TAM } & $-0,0126$ & $-0,0145$ & $-0,0142$ & 0,0138 & 1 & & & \\
\hline & 0,8972 & 0,8822 & 0,8846 & 0,9004 & & & & \\
\hline \multirow[t]{2}{*}{ LUC } & 0,1219 & 0,0914 & 0,0964 & 0,0050 & $-0,0790$ & 1 & & \\
\hline & 0,2119 & 0,3491 & 0,3230 & 0,9641 & 0,4188 & & & \\
\hline \multirow[t]{2}{*}{ TAG } & $-0,0700$ & $-0,0859$ & $-0,0834$ & 0,1262 & $-0,0396$ & $-0,0581$ & 1 & \\
\hline & 0,4739 & 0,3788 & 0,3933 & 0,2498 & 0,6851 & 0,5523 & & \\
\hline \multirow[t]{2}{*}{ OPC } & 0,108 & 0,1886 & 0,2402 & 0,6198 & 0,0241 & $-0,0874$ & 0,1607 & 1 \\
\hline & 0,3253 & 0,0838 & 0,0268 & 0,0000 & 0,8269 & 0,4265 & 0,1418 & \\
\hline
\end{tabular}

Nota. Os valores em negritos indicam correlações significativas.

Fonte: Dados da pesquisa (2018).

De acordo com a matriz de correlação verifica-se que os indicadores de alavancagem estão correlacionados entre si, o que já era de se esperar considerando que eles mensuram a mesma propriedade. Embora as correlações sejam quase perfeitas isso não corresponde a um problema em potencial, pois elas serão tratadas de maneira independente.

Ainda é possível verificar a relação da alavancagem com as oportunidades de crescimento, o coeficiente significativo e positivo coeficiente é inconsistente com a teoria perking order que assume uma associação negativa entre as variáveis (Fonseca, Silveira \& Kiratura, 2016), no entanto Jorge e Armada (2001) argumentam que embora exista essa proposição as pesquisas têm encontrado resultado contraditórios.

Quanto ao excesso de confiança, a variável não apresentou correlação nenhuma com o endividamento de curto e longo prazo, 
entretanto apresentou correlação significativa e positiva com o endividamento total, sugerindo que empresas com CEO mais confiantes se utilizam de maior grau de alavancagem total.

Também foi significativa a correlação do excesso de confiança com a oportunidade de crescimento, o que sugere que o grau de otimismo e excesso de confiança dos gestores aumentam à medida que as perspectivas de crescimentos também aumentam, entretanto, o indicador de correlação de 0,61 é indicado por Figueiredo Filho e Silva Júnior (2009) como moderada o que torna a proposição de associação frágil, e denotando a necessidade de métodos mais robustos de associação.

Embora a correlação represente um instrumento de associação entre as variáveis Brooks (2014) indica que ela representa apenas a associação linear entre as variáveis, o que não implica dizer que a variações de uma explique as variações sofridas por outra, tornando mais robusto a análise de regressão. A partir dessa premissa são apresentadas a seguir na tabela 6 o resultado do modelo de regressão OLS estimado para o indicador de endividamento de curto prazo.

A regressão apresentada na tabela 6 demonstrou a partir do teste de White a existência de heterocedasticidade, que segundo Gujarati e Porter (2011) é comum em cross-section. Para contornar o problema foi utilizada a correção de White, gerando assim o erro robusto apresentado na tabela. Como resultado, apenas uma das variáveis apresentou significância estatística, sendo ela o tamanho da organização.

A regressão não demonstrou relação entre o tamanho da empresa e o endividamento de curto prazo, conforme encontrado por Fonseca, Silveira e Hiratuka (2016), entretanto diferente da proxy aqui utilizada, os autores regrediram o logaritmo das vendas com o endividamento de curto prazo.

A rentabilidade apresentada na tabela 6 apresenta-se de acordo com o proposto por Araújo et al. (2017), pois representa a capacidade de geração de melhores resultado pela entidade, já Fonseca Silveira e Hiratuka (2016) indicam que os resultados mais comuns em trabalho envolvendo a estrutura de capital apresentam resultados negativos, a justificativa para tal resultado parte da teoria do parking order onde assimetria da informação resulta em uma preferência por fontes internas de financiamento. Embora o resultado seja consistente o coeficiente não foi significativo. 
Tabela 6 - Análise do Excesso de confiança no endividamento de curto prazo

\begin{tabular}{|c|c|c|c|}
\hline \multirow{2}{*}{$\begin{array}{l}\text { Variável dependente: } \\
\text { Variáveis independentes }\end{array}$} & \multicolumn{3}{|c|}{ Endividamento de curto prazo } \\
\hline & Coeficiente & Erro padrão & Teste $\mathrm{t}$ \\
\hline EXC_COF & $-0,05616$ & 0,07065 & 0,467 \\
\hline TAM & $-0,00872$ & 0,02163 & 0,688 \\
\hline REN & 0,20738 & 0,26226 & 0,432 \\
\hline TAN & 0,05045 & 0,11834 & 0,671 \\
\hline OPC & 0,03639 & 0,01517 & $0,019^{* *}$ \\
\hline Constante & 0,09140 & 0,36710 & 0,804 \\
\hline Observações & 76 & $\mathrm{R}$ quadrado ajustado & 0,1652 \\
\hline Teste $F(5,70)$ & $3,97^{* * *}$ & Teste de normalidade ( $\mathrm{p}$-valor) & $0,0000^{* * *}$ \\
\hline Teste de White & $30,56^{*}$ & Estatística VIF (média) & 1,25 \\
\hline
\end{tabular}

Nota. 1. O erro padrão apresentado corresponde ao robusto de White; $2{ }^{* * *}$ significativo a $1 \%$; ${ }^{* *}$ significativo a $5 \%$ e ${ }^{*}$ significativo a $10 \%$.

Fonte: Dados da pesquisa (2017).

Quanto ao indicador de tangibilidade, o contexto das teorias da estrutura de capital sugere uma relação positiva da variável com o grau de endividamento (Bastos \& Nakamura, 2009). No curto prazo o resultado se mostrou positivos, entretanto não significativo.

Apenas a variável de oportunidade de crescimento foi significativa no modelo implicando em uma relação positiva entre as variáveis. Gestores que subestima o crescimento dos ganhos futuros vê o financiamento externo como mais dispendioso, os títulos de riscos são vistos como subavaliados, ocorrendo uma relutância na emissão de títulos de capital e implicando na consistência com o pecking order, entretanto partindo do modelo tradeoff as preferências se invertem e a resposta do mercado racional ao aumento do número de ações em circulação ajusta o preço da ação de tal forma 
que o valor de mercado do capital próprio permaneça inalterado. O efeito do viés de percepção do risco aproxima os gestores da ideia de que sua empresa e menos propensa a dificuldade financeiras e sofrimento financeiro, o que torna preferível o financiamento por meio do capital próprio (Hackbarth, 2008).

A variável excesso não significativa demonstrou-se inconsistente com os trabalhos anteriores onde as empresas gerenciadas por gestores otimistas superestimaram a capacidade de endividamento da empresa (Barros \& Silveira, 2008). Os resultados aqui encontrado sugerem que em empresas que realizam abertura de capital tais efeitos não são aplicáveis.

A tabela 7 apresenta o resultado das regressões para a variável dependente endividamento de longo prazo.

\section{Tabela 7 - Análise do Excesso de confiança no endividamento de longo prazo}

\begin{tabular}{|c|c|c|c|}
\hline \multirow{2}{*}{$\begin{array}{l}\text { Variável dependente: } \\
\text { Variáveis independentes }\end{array}$} & \multicolumn{3}{|c|}{ Endividamento de longo prazo } \\
\hline & Coeficiente & Erro padrão & Teste $t$ \\
\hline $\mathrm{EXC} \mathrm{COF}_{-}$ & 0,08892 & 0,06589 & 1,35 \\
\hline TAM & 0,03688 & 0,01290 & $2,86^{* * *}$ \\
\hline REN & $-0,14166$ & 0,06461 & $-2,19 * *$ \\
\hline TAN & 0,22899 & 0,08065 & $2,84^{* * *}$ \\
\hline $\mathrm{OPC}$ & $-0,01779$ & 0,01044 & $-1,7^{*}$ \\
\hline Constante & $-0,50723$ & 0,28159 & $2,86^{*}$ \\
\hline Observações & 76 & R quadrado ajustado & 0,2298 \\
\hline Teste F $(5,70)$ & $5,48^{* * *}$ & $\begin{array}{l}\text { Teste de normalidade } \\
\text { (p-valor) }\end{array}$ & $0,0223^{* *}$ \\
\hline Teste de White & 28,35 & Estatística VIF (média) & 1,25 \\
\hline
\end{tabular}

Nota. ${ }^{* * *}$ significativo a $1 \%$; ${ }^{* *}$ significativo a $5 \% \mathrm{e}^{*}$ significativo a $10 \%$. Fonte: Dados da pesquisa (2017). 
No longo prazo conforme descrito pela tabela 7 diferente do curto a proxy para o tamanho da empresa foi significativa e positiva o que de acordo com Bastos e Nakamura (2009) é consistente com várias teorias acerca da estrutura de capital incluindo a perking order e a do trade-off já mencionadas no referencial teórico.

As variáveis relativas a rentabilidade e a tangibilidade também demonstram significância estatística, porém ambas demonstraram relação negativa, implicando que empresas com maior rentabilidade e tangibilidade apresentam menor alavancagem no longo prazo. Quanto ao excesso de confiança o resultado não demonstrou significância.

A última análise efetuada corresponde a relação do endividamento total com o viés de excesso de confiança. Os resultados da análise estão dispostos na tabela 8 .

Tabela 8 - Análise do Excesso de confiança no endividamento total

\begin{tabular}{|c|c|c|c|}
\hline \multirow{2}{*}{$\begin{array}{l}\text { Variável dependente: } \\
\text { Variáveis independentes }\end{array}$} & \multicolumn{3}{|c|}{ Endividamento total } \\
\hline & Coeficiente & Erro padrão & Teste $t$ \\
\hline EXC_COF & 0,03730 & 0,08579 & 0,43 \\
\hline TAM & 0,02815 & 0,01681 & $1,67^{*}$ \\
\hline REN & 0,06572 & 0,08413 & 0,78 \\
\hline TAN & 0,27944 & 0,10502 & $2,66^{* *}$ \\
\hline OPC & 0,01859 & 0,01359 & 1,37 \\
\hline Constante & $-0,41582$ & 0,36680 & $-1,13$ \\
\hline Observações & 76 & $\begin{array}{l}\text { R quadrado ajus- } \\
\text { tado }\end{array}$ & 0,1672 \\
\hline Teste $F(5,70)$ & $4,01^{* * *}$ & $\begin{array}{l}\text { Teste de normalida- } \\
\text { de (p-valor) }\end{array}$ & 0,2410 \\
\hline Teste de White & 25,49 & $\begin{array}{l}\text { Estatística VIF } \\
\text { (média) }\end{array}$ & 1,25 \\
\hline
\end{tabular}

Nota. ${ }^{* * *}$ significativo a $1 \%$; ${ }^{* *}$ significativo a $5 \%$ e ${ }^{*}$ significativo a $10 \%$.

Fonte: Dados da pesquisa (2017). 
Os resultados das regressões dispostas na tabela 8 confirmam os achados demonstrados nas regressões constantes nas tabelas 7 e 8, além de ser consistente com os resultados da análise de correlação. Assim como nas análises anteriores não há evidencias de que empresas que realizaram IPO tem sua estrutura de capital influenciada pela confiança excessiva dos gestores, não confirmando a hipótese de pesquisa 1 .

Os resultados apresentados diferem das pesquisas desenvolvidas com empresas de capital aberto efetuada por Barros e Silveira (2008), empresas de capital fechado efetuada por Cavalheiro (2015), empresas cinquentenárias estudadas por Silva et al. (2017) e empresas americanas estudadas por Costa, Correia e Lucena (2017).

\section{Considerações Finais}

O excesso de confiança corresponde ao traço de personalidade mais estudados nas finanças comportamentais. Segundo Brown e Sarma (2007) esse corresponde a um fenômeno generalizado, implicando que a substituição do gestor não implicaria na eliminação do viés. Como traço de personalidade é impossível eliminá-lo, entretanto é possível reduzi-lo através de um feedback adequado (Simon \& Houghton, 2003).

O excesso de confiança dos gestores influencia o processo decisório estratégico e são capazes de se relacionar positivamente a estrutura de capital das empresas, conforme demonstrado pelos estudos de Costa, Araújo e Lucena (2017); Silva et al. (2017), Cavaleiro (2015) e Barros e Silveira (2008). Embora esses trabalhos contratem as teorias tradicionais da estrutura de capital, elas não as excluem podendo pode estar relacionada tanto ao excesso de confiança como por exemplo a hierarquia das fontes de financiamento.

A diversidade de amostra e as relações significativa encontrada nas pesquisas citadas acima, sugerem uma relação quase que universal entre as duas variáveis, neste contexto, o presente trabalho teve por objetivo verificar o viés do excesso de confiança e sua relação com a estrutura de capital de empresas que realizaram ofertas públicas iniciais entre 2004 a 2017.

Neste período com a ampliação de crédito houve a retomada da abertura de capital no Brasil o que tornou esse o período ideal 
para a análise, segundo dados da Brasil, Bolsa, balcão (2018) foram encontradas 145 empresas das quais apenas 107 delas estavam aptas a integrarem a amostra da pesquisa, uma vez que foram definidos como critérios a disponibilidade dos dados e a caracterização como empresas não financeiras.

A partir de uma revisão da literatura optou-se por utilizar o indicador de endividamento como proxy para a estrutura de capital em três perspectivas distintas, total, de curto prazo e longo prazo, todos mensurados pela relação passivo sobre ativos totais. A média da alavangem no curto prazo corresponde a $36 \%$, já no longo prazo e total, a média (respectivamente 1,12 e 1,49) desse indicador sofreu uma forte influência da empresa Santo Brasil Participações que apresentou patrimônio líquido negativo no período, inflando a média.

A partir da metodologia do índice geral de confiança proposta por Kermani, Kargar e Zarei (2014) e representado pelos erros resultantes da regressão das variações das vendas e a variação dos ativos indica o excesso de confiança sempre que for positivo. Os resultados da análise demonstraram que apenas uma empresa não apresentara otimismo gerencial, corroborando a ideia de que o otimismo corresponde a uma característica generalizada que impacta os gestores de todos os setores e empresas, e ressaltando a importância dos feedbacks dessas decisões.

Embora trata-se de um fenômeno generalizado as correlações não evidenciaram essas relações, só foi possível verificar uma correlação positiva entre o excesso de confiança e o indicador de endividamento de longo prazo, porém dentro dos parâmetros estabelecidos por Figueiredo Filho e Silva Júnior (2009) trata-se de uma associação fraca e não há variáveis de controle nessa relação, por esse motivo adotou-se a metodologia da regressão múltipla.

As regressões não apresentaram significância estatística para a variável excesso de confiança e as variáveis dependente endividamento de curto, longo prazo ou total, não sendo possível estabelecer relação entre o entre o traço de personalidade do excesso de confiança na definição da estrutura de capital das empresas que realizam IPO, diferenciando do encontrado por Costa, Araújo e Lucena (2017); Silva et al. (2017), Cavaleiro (2015) e Barros e Silveira (2008). 
Diferente desses estudos, aqui foi utilizada o momento do IPO, onde a estrutura de capital passa ser mais impactada pelas fontes de financiamento e a empresa busca reduzir seu endividamento por meio da oferta pública. Mais que uma decisão financeira a abertura de capital corresponde a uma decisão estratégica, e que segundo dados da pesquisa realizada por Bomfim, Santos e Pimenta Júnior (2006) é apontado pelos gestores como resultado da valorizaram e a opinião dos investidores.

Dada a sua conotação estratégica, as implicações legais e financeiras, além da diversidade de processos ao qual Pinheiro (2012) cita transformação societária e de governança, adequações legais e melhoria da gestão pode concluir o IPO como um processo longo, onde reside uma possível explicação para os resultados obtidos, uma vez que o excesso de confiança se trata de uma heurística comportamental que atua como um atalho decisório em situações dinâmicas ou rápidas, não sendo o caso do IPO.

\section{REFERÊNCIAS}

Almendra, R. S., de Vasconcelos, A. C., Aragão, R. N., \& Cysne, I. A. (2017). Influência da estrutura de capital nos investimentos em inovação das indústrias listadas na BM\&FBOVESPA. Revista Eletrônica de Ciência Administrativa, 16(1), 40-61.

Araújo, J. G., Confessor, K. L. A., Santos, J. F., Oliveira, M. R. G., \& Prazeres, R. V. (2017). A estrutura de capital e a governança: análise dos conselhos administração e estrutura de propriedade nas empresas listadas no IBRX-100. Revista de Gestão, Finanças e Contabilidade, 7(2), 121-140.

Barros, L. A. B. C., \& Silveira, A. M. (2008). Excesso de confiança, otimismo gerencial e os determinantes da estrutura de capital. Revista Brasileira de Finanças, 6(3).

Basso, K., \& Espartel, L. B. (2015). O uso de traços de personalidade para a diferenciação de consumidores em níveis de lealdade distintos. Contextus-Revista Contemporânea de Economia e Gestão, 13(1), 7-33.

Bastos, D. D., \& Nakamura, W. T. (2009). Determinantes da estrutura de capital das companhias abertas no Brasil, México e Chile no período 2001-2006. Revista Contabilidade E Finanças, 20(50), 75-94.

Bomfim, L. P.M., Santos, C. M., \& Pimenta Júnior, T. (2007). Processos de abertura de capital de empresas brasileiras em 2004 e 2005: razões e percepções. RAUSP Management Journal, 42(4), 524-534.

Brasil, Bolsa, Balcão. (2018). Ofertas Públicas Iniciais. Recuperado de http://www.bmfbovespa. com.br/pt_br/servicos/ofertas-publicas/estatisticas. 
Lei $n^{\circ} 11638$ de 28 de dezembro de 2007. Altera e revoga dispositivos da Lei no 6.404, de 15 de dezembro de 1976, e da Lei no 6.385, de 7 de dezembro de 1976, e estende às sociedades de grande porte disposições relativas à elaboração e divulgação de demonstrações financeiras. Recuperado de http://www.planalto.gov.br/ccivil_03/_ato2007-2010/2007/lei/111638.htm.

Brooks, C. (2019). Introductory econometrics for finance. Cambridge university press.

Brown, R., \& Sarma, N. (2007). CEO overconfidence, CEO dominance and corporate acquisitions. Journal of Economics and business, 59(5), 358-379.

Cao, T. R., \& Montezano, R. M. D. S. (2016). Initial Public Offering And Performance Of Brazilian Firms. Revista de Gestão, Finanças e Contabilidade, 6(2), 160-178.

Cavalcanti, J. M. M., Castro, S. L., Avelar, E. A., Lazo, R. P., \& Mól, A. L. R. (2016). Financial Debt Stratification and Capital Structure determinants of companies listed in the BM\&FBOVESPA. Revista de Gestão, Finanças e Contabilidade, 6(3), 125-142.

Cavaleiro, Everton Anger.(2015). Determinantes da estrutura de capital das micro e pequenas empresas: Uma abordagem comportamental (Tese de doutorado). Universidade Federal de Santa Maria, Santa Maria, RS, Brasil.

Cavalheiro, E. A., Vieira, K. M., \& Valcanover, V. M. (2016). Estrutura de Capital das Micro e Pequenas Empresas Gaúchas: uma análise dos relacionamentos bancários e fontes de financiamento. Revista da Micro e Pequena Empresa, 10(2), 2.

Costa, I. L.S.; Correia, T. S.; Lucena, W. G. L. (2017). O Impacto do Excesso de Confiança na Estrutura de Capital: Evidências no Brasil e nos Estados Unidos. Anais do Congresso AMPCONT, Belo Horizonte, MG, Brasil, 11.

Cunha, P. R., Santos, C. A., \& Haveroth, J. (2017). Fatores contábeis explicativos da política de estrutura de capital dos clubes de futebol brasileiros. Podium Sport, Leisure and Tourism Review, 6(1), 01-21.

Ferreira, C. F., \& Yu, A. S. O. (2003). Todos acima da média: excesso de confiança em profissionais de finanças. Revista de Administração-RAUSP, 38(2), 101-111.

Figueiredo Filho, D. B., \& Silva Júnior, J. A. D. (2009). Desvendando os Mistérios do Coeficiente de Correlação de Pearson (r).

Fonseca, C. V.C., Silveira, L. F., \& Hiratuka, C. (2016). A relação entre a governança corporativa e a estrutura de capital das empresas brasileiras no período 2000-2013. Enfoque: reflexão contábil, 35(2).

Gujarati, D. N., \& Porter, D. C. (2011). Econometria Básica (5ª ed.). Bookman Editora.

Hackbarth, D. (2008). Managerial traits and capital structure decisions. Journal of Financial and Quantitative Analysis, 43(4), 843-881.

Heaton, J. B. (2002). Managerial optimism and corporate finance. Financial management, 33-45.

Jorge, S., \& Armada, M. J. D. R. (2001). Fatores determinantes do endividamento: uma análise em painel. Revista de Administração Contemporânea, 5(2), 9-31. 
Junqueira, L. R.; Soares, C. H.; Bressan, A. A.; Bertucci, L. A. (2017). Impactos da adesão aos níveis diferenciados de Governança Corporativa sobre a Estrutura de Capital das empresas brasileiras. Revista de Administração da Universidade Federal de Santa Maria, 10(3).

Kermani, E.; Kargar, E. F.; Zarei, E. (2014). The Effect of Managerial Overconfidence on Profit Smoothing Evidence from Tehran Stock Exchange. Research Journal of Finance and Accounting. Research Journal of Finance and Accounting, 5(9), 111-119.

La Rocca, M., La Rocca, T., \& Cariola, A. (2009). Capital structure decisions during a firm's life cycle. Small Business Economics, 37(1), 107-130.

Langabeer, J. R., \& DelliFraine, J. (2011). Does CEO optimism affect strategic process?. Management Research Review, 34(8), 857-868.

Tonin, J. M. F., Oliveira, A. M., Soares, R. O., Frega, J. R. (2016). Efeito do excesso de confiança e otimismo na suavização de resultados nas empresas listadas na BM\&FBOVESPA. Anais do SEMEAD, São Paulo, SP, Brasil, 19.

Lim, R. G. (1997). Overconfidence in negotiation revisited. International Journal of Conflict Management, 8(1), 52-79.

Malmendier, U., \& Tate, G. (2005). CEO overconfidence and corporate investment. The journal of finance, 60(6), 2661-2700.

Malmendier, U., \& Tate, G. (2008). Who makes acquisitions? CEO overconfidence and the market's reaction. Journal of financial Economics, 89(1), 20-43.

McCrae, R. R., \& Costa Jr, P. T. (1997). Personality trait structure as a human universal. American psychologist, 52(5), 509.

Medeiros, R., de Carvalho Ferreira, A., Menezes, J. P. C. B., dos Santos Sant'ana, N. L., \& de Lima, S. A. (2017). Relação entre Estrutura de Capital de empresas brasileiras negociadas na NYSE e a variação da SELIC. Revista de Gestão, Finanças e Contabilidade, 7(3), 230-246.

Modigliani, F., \& Miller, M. H. (1958). The cost of capital, corporation finance and the theory of investment. The American, 1, 3.

Myers, Stewart C. (2001). Capital Structure. Journal of Economic Perspectives, 15(2), 81-102.

Myers, S. C. (1984). The capital structure puzzle. The journal of finance, 39(3), 574-592.

Oliveira, B. C., \& Martelanc, R. (2014). IPO determinants of Brazilian companies. Brazilian Review of Finance, 12(2), 135-161.

Paunonen, S. V. (1998). Hierarchical organization of personality and prediction of behavior. Journal of Personality and Social Psychology, 74(2), 538.

Peterson, C. (2000). The future of optimism. American psychologist, 55(1), 44.

Pinheiro, J. L. (2012). Mercado de capitais: fundamentos e técnicas (6 ${ }^{\underline{a}}$ ed.). São Paulo: Atlas.

Shefrin, H. (2001). Behavioral corporate finance. Journal of applied corporate finance, 14(3), 113-126. 
Silva, T. B., Mondini, V. E. D., Silva, T. P., \& Lay, L. A. (2017). Influência do Excesso de Confiança e Otimismo no Endividamento de Organizações Cinquentenárias e não Cinquentenárias Brasileiras. Revista Evidenciação Contábil \& Finanças, 5(2), 40-56.

Simon, M., \& Houghton, S. M. (2003). The relationship between overconfidence and the introduction of risky products: Evidence from a field study. Academy of Management Journal, 46(2), 139-149.

Tversky, A., \& Kahneman, D. (1974). Judgment under uncertainty: Heuristics and biases. science, 185(4157), 1124-1131.

Zilio, A. (2012). Decisão das empresas de realizar um IPO e implicações sobre desempenho: uma análise da experiência brasileira (Dissertação de mestrado). Universidade de São Paulo, São Paulo, SP, Brasil.

Recebido em: 16-3-2021

Aprovado em: 2-12-2021

Avaliado pelo sistema double blind review.

Disponível em http://mjs.metodista.br/index.php/roc 